\title{
Mathematical Modeling of Investors' Savings Plan (ISP) with Stochastic Interest Rate via Numéraire Change
}

\author{
Philip Ajibola Bankole ${ }^{1, *}$, Adeniyi Adewopo \\ ${ }^{1}$ Department of Mathematics, University of Ibadan, Ibadan, Nigeria \\ ${ }^{2}$ Department of Physics, Adeniran Ogunsanya College of Education, Oto/Ijanikin, Nigeria \\ Email address: \\ pa.bankole@yahoo.com (P. A. Bankole), adewopon@yahoo.co.uk (A. Adewopo) \\ ${ }^{*}$ Corresponding author
}

\section{To cite this article:}

Philip Ajibola Bankole, Adeniyi Adewopo. Mathematical Modeling of Investors' Savings Plan (ISP) with Stochastic Interest Rate via Numéraire Change. International Journal of Theoretical and Applied Mathematics. Vol. 3, No. 1, 2017, pp. 25-29.

doi: $10.11648 /$ j.ijtam.20170301.14

Received: October 31, 2016; Accepted: December 10, 2016; Published: January 7, 2017

\begin{abstract}
This paper focuses on Numéraire change technique for pricing financial assets with stochastic interest rate. It makes sense to introduce the notion of stochastic interest rate when dealing with long term option pricing problems rather than constant interest rate addressed in the past by most papers. We consider the application of Numéraire Change technique to pricing of Investor's Savings Plan (ISP) with swaption between two interest rates, inflation and exchange rates of two different countries. The result shows that it is better to incorporate stochastic interest rate into long term option pricing problems and Numéraire technique is better applied if faced with several risks factors.
\end{abstract}

Keywords: Numéraire Change, Stochastic Interest Rate, Investor Savings Plan (ISP)

\section{Introduction}

Numéraire is a standard unit by which we measure the values of portfolio of assets. Portfolio of assets consist of both risky and risk free assets. One of the most typical cases of several risk factors occurs when an option is to choose between two assets with stochastic prices. Change of Numeraire technique helps in reducing the number of sources of risk which need to be accounted for while handling portfolio of assets $[4,6,19]$. Changing Numeraire implies a change in probability measure. Switching from one Numeraire to another and hence by a measure to another is to ease computational process (see [15, 17, 17, 19]).

A typical example of a Numeraire is the currency of a country, because people usually measure other asset's price in terms of the unit of currency. The revolutionary approach to pricing and risk-managing of contingent claims was developed by Black-Scholes and Merton (1973), which still remains very important tool till today [21]. This model assumes that the asset price is driven by a geometric Brownian motion with constant volatility with no jumps and default risk, so, principally, it cannot be applied in its original form for pricing and hedging of many derivative products traded in today's marketplace, such as options on realized volatility or credit default swaps $[21,22]$. We intend to collapse the notion of constancy in some of the parameters that define the livelihood of portfolio of asset such as the interest rate, inflation rate, exchange rate, volatility etc. We argued out in this article that if a financial pricing problem has a long term maturity, then there is strong probability of fluctuations in the interest rates. Also, if the pricing problem is linked with international exchange, then the exchange rate also could be stochastic over time.

The option pricing model by Black and Scholes (1973) and the term structure model by Ho and Lee (1986) are among the most leading models of capital market theory [19]. While Black/Scholes consider stock option prices under the assumption of a constant deterministic interest rate, Ho and Lee were the first to model the term structure of interest rates as a stochastic entity.

The pioneer approach to pricing and hedging financial derivatives was proposed by Black-Scholes and Merton (1973), who suggested the use of the log-normal diffusion to model the asset price evolution in time:

$$
\mathrm{dS}(\mathrm{t})=\mu \mathrm{S}(\mathrm{t}) \mathrm{dt}+\sigma \mathrm{S}(\mathrm{t}) \mathrm{dW}(\mathrm{t}) ; S(0)
$$


is given where $\mu$ is asset drift which measures the expected return associated with $S(t), \sigma$ is asset volatility which measures variability of returns on $S(t)$, and $W(t)$ is a standard Brownian motion used as a tool in modeling the variability of the asset price dynamics. It follows that options need to be priced under the so-called risk-neutral or martingale measure $\mathrm{Q}$, under which the discounted price of any derivative security, including the asset price itself, is a martingale and the risk-neutral drift of any security is equal to risk-free rate of return $r$. So an Equivalent Martingale Measure (EMM) is a Risk Neutral Measure. See [6, 9, 10, 12] for more explanation on Equivalent Martingale Measure. Some papers have contributed to option pricing with stochastic interest rates recently. See $[1,2,3]$. For example, Haowen F. (2012) used martingale method to study the stochastic interest rate model of European option pricing. Stochastic interest rate was expressed as Vasicek Stochastic Differential equations and European option pricing formula was obtained in the paper. See [7].

\section{Numéraire Framework}

Definition 2.1: A Numeraire is any asset with price process $N(t)$ such that $N(t)>0$, for all time $t$. [16, 17, 18, ] Numéraire could be in terms of currency, bond, bank account etc.

Definition 2.2: For $p \geq 1$, an adapted process $X$ is called a $[$ closed $] L^{p}$-martingale (resp. Super-martingale, Sub-martingale) w.r.t. the filtration $\mathrm{F}$ if for all $t \in R_{+} \quad\left[t \in \overline{\mathbf{R}}_{+}\right]$,

$$
\text { 1. } X_{t} \in L^{p}(P) \text {; that is, } E\left(\left|X_{t}\right|^{p}\right)<\infty
$$

2. if $s \leq t$, then $\mathrm{E}\left(X_{t} \mid \mathrm{F}_{s}\right)=X_{s}$ a.s. ( resp. $\mathrm{E}\left(X_{t} \mid \mathrm{F}_{s}\right) \leq X_{s}$

$$
\text { and } \left.\mathrm{E}\left(X_{t} \mid \mathrm{F}_{s}\right) \geq X_{s}\right) \text {. }
$$

Remarks: 1. If $\sup _{t \in R_{+}} E\left(\left|X_{t}\right|^{p}\right)<\infty$, then $X$ is moreover called $L^{p}$-bounded. An $L^{1}$-martingale is also referred to as a martingale. On a finite time interval $[0, T]$ all martingales are closed and we say martingale $X$ is closed by the value $X_{T}$ ( or $X_{\infty}$ in the infinite case).

2. For a process to be a martingale, it is reliant on the filtration (conditioning) as well as the probability measure (expectation). Hereafter, we denote this by saying $X$ is a $(\mathrm{F}, P)$-martingale in this paper.

3 . The right continuity assumption for a standard filtration ensures c'adl'ag versions for martingales and certain super(sub-) martingales.

$$
\text { Definition 2.3: Let } V(t)=\sum_{k=0}^{n} \omega_{k}(t) S_{k}(t) \text {. }
$$

A portfolio strategy is called self-financing if the stochastic integrals $\int_{0}^{T} \omega_{k}(t) d S_{k}(t)$ exist for each $k$ and $d V(t)=\sum_{k=0}^{n} \omega_{k}(t) d S_{k}(t)$

Proposition 2.4: A self-financing portfolio of assets remains self-financing after change of Numeraire. See [15]. We apply the following theorems without showing the proof here. We shall see the evidence of this in sequel.

Bayes' Formula: Let $P$ and $Q$ be an equivalent probability measures on the measurable $\operatorname{space}(\Omega, \mathrm{F})$ and $H$ a sub- $\sigma$-algebra of $\mathrm{F}$. If $Y \geq 0$ is in $L^{1}(\Omega, \mathrm{F}, I P)$ and in $L^{1}(\Omega, \mathrm{F}, Q)$, then we have the identity

$$
\mathrm{E}_{P}\left[Y \frac{d Q}{d P} \mid \mathrm{H}\right]=\mathrm{E}_{Q}[Y \mid \mathrm{H}] \mathrm{E}_{I P}\left[\frac{d Q}{d P} \mid \mathrm{H}\right] \quad \text { a.s. }(Q) .
$$

Theorem 2.5 (Girsanov): Girsanov Theorem represents the foundation of the change of measure toolkit (see [15]). For the statement of the theorem, see [11].

Let $(\Omega, F, P)$ be a probability space, and $\Lambda$ be a random variable such that $\Lambda \geq 0$ almost surely and $E \Lambda=1$. Then we can define a measure $Q$ on $(\Omega, F)$ by

$$
Q F=\int_{F} \Lambda d P
$$

$\Lambda$ is often written $d Q / d P$ and is the Radon-Nikodym derivative of $Q$ with respect to $P$.

The Radon-Nikodym theorem states that any $\mathrm{Q}$ that is absolutely continuous with respect to $\mathrm{P}$ can be written as "(6)" for some $\Lambda$. If $\Lambda>0$ almost surely, then $P$ is absolutely continuous with respect to $\mathrm{Q}$, with Radon Nikodym derivative $\mathrm{dP} / \mathrm{dQ}=1 / \Lambda$. In this case $\mathrm{P}$ and $\mathrm{Q}$ are said to be equivalent. Measures $\mathrm{P}$ and $\mathrm{Q}$ are equivalent if and only if they have the same null sets: $\mathrm{PF}=0, \mathrm{QF}=0$.

Proposition 2.6: Let $M(t)$ be non-dividend paying numéraire with $\frac{M(t)}{N(t)}$ a $\pi$-martingale. Then, there exists a probability measure $Q_{M}$ defined via its Radon-Nikodym derivative relative to $\pi$ as

$$
\left.\frac{d Q_{M}}{d \pi}\right|_{\mathrm{F}_{T}}=\frac{M(T)}{M(0) N(T)}
$$

such that

(i) the discounted securities are $Q_{M}$-local martingales.

(ii) if a contingent claim $H$ has a fair price under $(N, \pi)$, then it has a fair price under $\left(M, Q_{M}\right)$ and the hedging portfolioremain unchanged.

Proof: (i) Suppose $\bar{S}(t)=\frac{S(t)}{N(t)},\left(S^{*}(t)=S(t) / M(t)\right)$ is the relative price of an asset $S$ with respect to the old (new) numéraire $N(M)$. We only consider the case where $\bar{S}(t)$ is a $\pi$-martingale, but the localization case follows similar way. 
Then $\left.\quad \frac{d Q_{M}}{d \pi}\right|_{T}=\frac{\bar{M}_{T}}{M(0)} \quad$ satisfies $\mathrm{E}_{\pi}\left(\frac{d Q_{M}}{d_{\pi}} \mid \mathrm{F}_{t}\right)=\frac{\bar{M}(t)}{M(0)}$ because by hypothesis, $\bar{M}$ is a $\pi$-martingale and $M_{0}$ is $\mathrm{F}_{t}$ -measurable $\forall t \geq 0$. Applying Bayes' formula (5) gives:

$$
\begin{gathered}
\mathrm{E}_{Q_{M}}\left[S^{*}(T) \mid \mathrm{F}_{t}\right] \frac{\bar{M}(t)}{M(0)}=\mathrm{E}_{Q_{M}}\left[S^{*}(T) \mid \mathrm{F}_{t}\right] \mathrm{E}_{\pi}\left[\frac{d Q_{M}}{d \pi} \mid \mathrm{F}_{t}\right] \\
=\mathrm{E}_{\pi}\left[\frac{d Q_{M}}{d \pi} S^{*}(T) \mid \mathrm{F}_{t}\right] \\
=\mathrm{E}_{\pi}\left[\left(\frac{M(T)}{N(T) M(0)}\right)\left(\frac{S(T)}{M(T)}\right) \mid \mathrm{F}_{t}\right] \\
=\frac{1}{M_{0}} \mathrm{E}_{\pi}\left[\bar{S}(T) \mid \mathrm{F}_{t}\right]=\frac{1}{M_{0}} \bar{S}_{t} .
\end{gathered}
$$

again because of the $\pi$-martingale property and $X_{0}$ being $\mathrm{F}$-measurable $\forall t \geq 0$.

Thus, we have

$$
\mathrm{E}_{Q_{M}}\left[S^{*}(T) \mid \mathrm{F}_{t}\right]=\frac{S(t)}{M(t)}=S^{*}(t)
$$

and $S^{*}$ is a $Q_{M}$-(local) martingale.

Proof: (ii) Suppose $H$ has a fair price under $(N, \pi)$, then $\bar{V}_{t}=\mathrm{E}_{\pi}\left[H(T) / N(T) \mid \mathrm{F}_{t}\right]$ is the value process of a selffinancing portfolio generating $H$. With

$$
\begin{gathered}
\mathrm{E}_{\pi}\left[\frac{H(T)}{N(T)} \mid \mathrm{F}_{t}\right]=\mathrm{E}_{Q_{M}}\left[\frac{H(T)}{M(T)} \mid \mathrm{F}_{t}\right] \mathrm{E}_{\pi}\left[\frac{M(T)}{N(T)} \mid \mathrm{F}_{t}\right] \\
=\mathrm{E}_{Q_{M}}\left[\frac{H(T)}{M(T)} \mid \mathrm{F}_{t}\right]\left[\frac{M(t)}{N(t)}\right) \\
N(t) \mathrm{E}_{\pi}\left[\frac{H(T)}{N(T)} \mid \mathrm{F}_{t}\right]=V(t)=M(t) \mathrm{E}_{Q_{M}}\left[\frac{H(T)}{M(T)} \mid \mathrm{F}_{t}\right]
\end{gathered}
$$

We have a fair price and $\mathrm{E}_{Q_{M}}\left[\frac{H(T)}{M(T)} \mid \mathrm{F}_{t}\right]$ is also selffinancing and the hedging portfolio is invariant.

Corollary 2.7: Suppose $M$ and $N$ are two numéraire, the general numéraire change can be written at any time $t<T$ as

$$
M(t) \mathrm{E}_{Q_{M}}\left[N(T) \Xi \mid \mathrm{F}_{t}\right]=N(t) \mathrm{E}_{Q_{Y}}\left[M(T) \Xi \mid \mathrm{F}_{t}\right]
$$

with $\Xi$ any random $\mathrm{F}_{T}$-measurable cash flow and

$$
\frac{d Q_{M}}{d Q_{N}}=\frac{M(T)}{M(0)} / \frac{N(T}{N(0)}
$$

The two measures are equivalent (thus also equivalent to the market measure $P$ ), because the numéraires are strictly positive almost surely. The idea is simply to multiply by the old numeraire and divide by the new numeraire. Hence, the result follows.

\section{Main Result}

Investor's Saving Plans (ISP)

Investors have the option to choose the interest rate to be paid on their account under this plan. The investors have the choice at maturity between an indexed linked domestic interest rate growth or foreign interest rate growth of investment. As an illustration an investor may hold an option between the growth in Naira currency linked to Nigeria inflation or growth in the Euro currency. In other words, the investor holds partially a swaption between two interest rates of different currencies. A sensible investment analysis will show that there exists an interplay among interest rates, foreign Exchange rate and Inflation rate. In this article, we chose domestic and foreign risk neutral measures $\mathrm{Q}_{\mathrm{d}}$ and $\mathrm{Q}_{\mathrm{f}}$ capable of pricing the Asset (ISP) at hand in the presence of stochastic interest rates $r_{d}=r\left(X_{t}\right)$ and $r_{f}=r\left(Y_{t}\right)$ respectively linked with the underlying assets in time $\mathrm{T}>0$. We give the payoff of this pricing problem for one unit of domestic currency as:

$$
\Lambda\left(T, C_{d o m}\right)=\max \left[e^{r_{d} T} \mathrm{I}(T), e^{r_{f} T} \frac{E(T)}{E(0)}\right],
$$

with $r_{d}$ and $r_{f}$ representing the domestic and foreign stochastic riskless rates in that order, I is the domestic inflation process and $E$ the exchange rate of the domestic currency per foreign currency. The payoff in terms of the foreign currency is written as

$$
\Lambda\left(T, C_{f o r}\right)=\max \left(e^{r_{d} T} \frac{\mathrm{I}(T)}{E(T)}, \frac{e^{r_{f} T}}{E(0)}\right]=\left(e^{r_{d} T} \frac{\mathrm{I}(T)}{E(T)}-\frac{e^{r_{f} T}}{E(0)}\right)^{+}+\frac{e^{r_{f} T}}{E(0)} .
$$

Under the risk-neutral measure $Q_{f}$ for the foreign market numéraire (the long term-rate process in the foreign market) the time t price of the claim is given as

$$
\begin{aligned}
& \Lambda\left(t, C_{f o r}\right)=e^{r_{f} t} \mathrm{E}_{Q_{f}}\left[e^{r_{f} T}\left(\left(e^{r_{d} T} \frac{\mathrm{I}(T)}{E(T)}-\frac{e^{r_{f} T}}{E(0)}\right)^{+}+\frac{e^{r_{f} T}}{E(0)}\right) \mid \mathrm{F}_{t}\right] \\
= & e^{r_{f} t} \mathrm{E}_{Q_{f}}\left[\left(e^{\left(r_{d}-r_{f}\right) T} \frac{\mathrm{I}(T)}{E(T)}-\frac{1}{E(0)}\right)^{+} \mid \mathrm{F}_{t}\right]+\frac{1}{E(0)} e^{r_{f} t},
\end{aligned}
$$

There is a trace of European call option with strike price $E^{-1}(0)$ in the above equation. In order to price the claim, we introduced dynamics:

$$
\frac{d E_{t}}{E_{t}}=\left(r_{d}-r_{f}\right) d t+\sigma^{E} d W_{t}^{1},
$$




$$
\frac{d \mathrm{I}_{t}}{\mathrm{I}_{t}}=\gamma_{\mathrm{I}} d t+\left[\rho d W_{t}^{1}+\sqrt{1-\rho^{2}} d W_{t}^{2}\right]
$$

where $\sigma^{E}$ and $\sigma^{\mathrm{I}}$ represent the individual volatilities and $\rho$ the immediate correlation between $E$ and I . The Brownian motions are with respect to $Q_{d}$, the risk-neutral measure for the domestic market numéraire. Setting $B=\frac{\mathrm{I}}{E}$, we have

$$
\frac{d B_{t}}{B_{t}}=\left(\gamma_{\mathrm{I}}-r_{d}+r_{f}\right) d t+\left(\sigma^{E}-\sigma^{\mathrm{J}} \rho\right) d W_{t}-\left(\sigma \sqrt{1-\rho^{2}} d W_{t}\right),
$$

under the measure $Q_{f}$. One can easily see that the dynamics for $S_{t}=\exp \left[\left(r_{d}-r_{f}\right) t\right] B_{t}$ is

$$
\frac{d S_{t}}{S_{t}}=\gamma_{\mathrm{I}} d t+\sigma d W_{t}
$$

where $\sigma$ is the total volatility

$$
\sigma=\sqrt{\left(\sigma^{E}\right)^{2}+\left(\sigma^{\mathrm{I}}\right)^{2}+2 \sigma^{E} \sigma^{\mathrm{I}} \rho} .
$$

Our pricing problem lessens to

$$
\Lambda\left(t, C_{f o r}\right)=e^{r_{f} t} \mathrm{E}_{Q_{f}}\left[\left(S(T)-E^{-1}(0)\right)^{+} \mid \mathrm{F}_{t}\right]+E^{-1}(0) e^{r t^{t}},
$$

which involves a call option on $S$ with dividend rate $\gamma$ and strike price $E^{-1}(0)$. The foreign long term rate is already integrated in the formula. In the sense of Black-ScholesMerton formula, we write the price of the Asset as

$$
\begin{gathered}
\Lambda\left(t, C_{f o r}\right)=e^{r_{f} t}\left(S_{t} e^{\gamma_{1}(T-t)} \Phi\left(d_{1}(t)\right)-E^{-1}(0) \Phi\left(d_{2}(t)\right)\right)+E^{-1}(0) e^{r_{f} t} \\
=e^{\left(r_{d}-\gamma_{1}\right) t} \frac{\mathrm{I}(t)}{E(t)} e^{\gamma_{\mathrm{I}} T} \Phi\left(d_{1}(t)\right)-e^{r_{f} t} E^{-1}(0) \Phi\left(d_{2}(t)\right)+E^{-1}(0) e^{r_{f} t} \\
d_{1}(t)=\frac{1}{\sigma \sqrt{T-t}}\left\{\log \left(\frac{\mathrm{I}(t) E(0)}{E(t)}\right)+\left(r_{d}-r_{f}\right) t+\left(\gamma_{1}+\frac{1}{2} \sigma^{2}\right)(T-t)\right\} \\
d_{2}(t)=d_{1}(t)-\sigma \sqrt{T-t}
\end{gathered}
$$

We change the Price of the Asset in Domestic currency as follows:

$$
\begin{gathered}
\Lambda\left(t, C_{d o m}\right)=E(t) \Lambda\left(t, C_{f o r}\right) \\
=e^{\left(r_{d}-\gamma_{\mathrm{I}}\right) t} \mathrm{I}(t) e^{\gamma_{1} T} \Phi\left(d_{1}(t)\right)-e^{r_{f} t} \frac{E(t)}{E(0)} \Phi\left(d_{2}(t)\right)+\frac{E(t)}{E(0)} e^{r_{f} t} .
\end{gathered}
$$

with the condition that

$$
E(0) \neq 0 \text {. }
$$

\section{Conclusion}

In this paper, we have been able to incorporate stochastic interest rate into the Numeraire change technique for valuing an Investor's Saving Plan (ISP) contingent claim on a stock driven by Brownian motion. The idea we created here is that whenever one is considering a Financial Pricing problem with a long term maturity date, the interest rate may change over time and thus become stochastic in nature. Therefore, it is advisable to handle the interest rate stochastically in the pricing problem. Stochastic Interest rate may be written in terms of Geometric Brownian motion, depending on the problem and the method of pricing one is considering, if that is the case, and then one can solve the SDE using the appropriate method. The application of the stochastic interest rate may not be limited to the above (ISP) problem only; it can be extended to other pricing problems with long term maturity date. Also, Stochastic Interest rate may not be limited to Numeraire change technique only; it can be extended to other pricing methods when considering long term maturity asset pricing problems.

\section{References}

[1] Michael, J. B. and Yihong X. (2000), Stochastic Interest Rates and the Bond-Stock Mix, Kluwer Academic Publishers, European Finance Review 4: 197-210.

[2] Eun-Jung N., Jeong-Hoon, K. (2011), An Optimal Portfolio model with stochastic volatility and stochastic interest rate, Journal of Mathematical Analysis and Applications 375 (2) $510-522$.

[3] Mi-Hyun K., Jeong-Hoon, K. and Ji-Hoon, Y. (2015), Optimal Portfolio selection under stochastic volatility and stochastic interest rates. DOI: 10.12941/jksiam.2015.19.417

[4] Benninga, S., Björk, T. and Winner, Z., (2002), On the Use of Numéraire for pricing Futures, Forwards and Options, The Review of Financial Studies Winter, Vol. 12, No. 5, pp. $1143-$ 1163.

[5] Carr, P. and Chesney, M., (1996), American Put Call Symmetry, Working Paper, pp. 1-25.

[6] Dalang, R. C., and Morton, W. Willinger, (1990), Equivalent Martingale Measures and No-Arbitrage in Stochastic Securities Market Models. Stochastic and Stochastic Reports, Vol. 29, pp. 185-201.

[7] Damiano, B. and Fabio, M., (2001), Interest Rate ModelsTheory and Practice with Smile, Inflation and Credit, 2nd Edition, Springer Verlag.

[8] Haowen F. (2012), Option Pricing Under Stochastic Interest Rates, I. J. Engineering and Manufacturing, Published Online June 2012 in MECS (http://www.mecs-press.net) DOI: 10.5815/ijem. Pp. 82-89.

[9] Delbaen, W. and Shirakawa, H., (2002), A Note of Option Pricing for Constant Elasticity of Variance Model.

[10] Delbaen, W. and Schachermayer, (2005), The Mathematics of Arbitrage. Springer, Berlin Heidelberg New York. pp. 1-27. 
[11] Andrew L. (2008), Girsanov, Numeraires, and all that, pp. 1-9.

[12] Elliott, R. J. and Kopp, P. E., (2005), (Mathematics of Financial Markets). 2nd Edition, Springer, New York.

[13] Farshid, J., (1989), An exact Bond Option Pricing Formula, The Journal of Finance 44 , pp. 205-209.

[14] Farshid, J., Fein, M., (1990), Closed Form Solutions for Oil Futures and European Options in the Gibson Schwartz Model, Working Paper, Merrill Lynch Capital Markets. pp. 1-27.

[15] AntonioMannolini, (2014), Advanced Financial Modelling, A Crash review of the Change of Measure Theory. Lecture note 4, pg 1-9.

[16] Gawie, L. R., (2007), Applications of Change of Numéraire for Option Pricing. pp. 1-60.

[17] Geman, H. E., El Karoui, and Rouchet, J., (1995), Changes of Numeraire, Changes of Probability Measure and Option Pricing, Journal of Applied Probability, 32 pp. 443-458.
[18] Hull, J., and White, A., (1987), The Pricing of Options on Assets with Stochastic Volatilities, Journal of Finance 42 : 271-301.

[19] Jamshidian, F., (2008), Numéraire Invarince and Application to Option Pricing and Hedging, pp. 1-7.

[20] Jochen Wilhelm, (1986), Option Prices with Stochastic Interest Rates Black/Scholes and Ho/Lee unified. ISSN 14353539 , pp 1-10.

[21] Black, F., Scholes, M., (1973). The Pricing of Options and Corporate Liabilities, in: Journal of Political Economy, 81 (1973), 637-654.

[22] Mark, S., (1999), Changes of Numéraire for Pricing Futures, forwards and Options, The Review of Financial Studies Winter, Vol. 12, No. 5, pp. 1143-1163.

[23] Mark, H. A. Davis (2006), Mathematical Option Pricing, Imperial College, London, pp. 33-36. 